\title{
Os cuidados de enfermagem na sala de imunização
}

\author{
Rosimeire Monte de Santana*, Jose Eduardo Ribeiro Honorio Junior, D.Sc. ${ }^{* *}$
}

*Enfermeira, Faculdade Integrada da Grande Fortaleza (FGF), Ceará, ${ }^{* *}$ Biólogo, Professor Doutor Adjunto da Faculdade Integrada da Grande Fortaleza (FGF)

\section{Resumo}

Introdução: A falta de observaçôes nos cuidados de enfermagem na sala de vacinação podem trazer sérias consequências para os usuários do serviço de saúde, daí a necessidade de conhecermos melhor sua atuação no âmbito da imunização. Objetivos: Observar os cuidados de enfermagem envolvendo a vacinação. Material e métodos: Trata-se de um estudo bibliográfico, descritivo, qualitativo, exploratório acerca da temática. Foram consultados periódicos indexados na Lilacs, Medline, Scielo, entre outros, publicados no período de 2002 a julho de 2012. Resultados: Foram encontrados 85 artigos, mas somente 24 artigos foram utilizados por estarem de acordo com o tema da pesquisa. Conclusão: Foi constatada a importância dos cuidados com a aplicação, conservação e armazenamento dos imunobiológicos e principalmente um aperfeiçoamento técnico constante.

Palavras-chave: vacinação, sala de vacina, papel do profissional de enfermagem.

\section{Abstract}

\section{Nursing care in the vaccination room}

Introduction: The lack of observations in nursing care in the vaccination room can have serious consequences for users of health service, hence the need of better knowledge on their performance concerning immunization. Objectives: To observe the nursing care involving vaccination. Methods: This was a descriptive, qualitative and exploratory literature review regarding this theme. We consulted journals indexed in Lilacs, Medline and Scielo, among others, which are published from 2002 to 2012. Results: We found 85 articles, but only 24 articles were used in this study. Conclusion: We noted the importance of caring for the implementation, maintenance and storage of immunobiologics and mainly training in continuous improvement techniques.

Key-words: vaccination, immunization room, nurse’s role. 


\section{Resumen}

\section{Cuidados de enfermería en la sala de vacunación}

Introducción: La falta de observaciones en los cuidados de enfermería en la sala de vacunación puede traer graves consecuencias para los usuarios de los servicios de salud, de ahí la necesidad de un mejor conocimiento sobre la actuación de estos profesionales en la actividad de inmunización. Objetivos: Observar los cuidados de enfermería que envuelven la vacunación. Material y métodos: Se trata de una investigación bibliográfica, descriptiva, cualitativa, exploratoria sobre el tema. Hemos consultado revistas indizadas en Lilacs, Scielo Medline, entre otros, que fueron publicadas entre 2002 y 2012. Resultados: Se encontraron 85 estudios, pero sólo 24 artículos eran acerca del tema investigado. Conclusión: Se señaló la importancia de cuidar para la ejecución, mantenimiento y almacenamiento de inmunobiológicos y principalmente el continuo perfeccionamiento técnico.

Palabras-clave: vacunación, sala de vacunación, rol de la enfermera.

\section{Introdução}

As formas mais antigas de vacinação descrevem a aplicação em adultos e crianças de material obtido das lesóes da pele em casos de varíola de menor gravidade. Era uma prática perigosa e uma parte dos inoculados faleciam pela doença, mas em menor número que os $20 \%$ a $30 \%$ dos que faleciam da infecção natural. No entanto, o médico inglês Edward Jenner, aprimorou essa técnica, surgindo a primeira vacina contra a varíola em 1798 [1].

No Rio de Janeiro, no início do século XX, a falta de saneamento básico e as péssimas condiçóes de higiene faziam da cidade um foco de epidemias, principalmente febre amarela, varíola e peste. Estas pragas tropicais deram à capital do país o triste apelido de "túmulo de estrangeiros". Com medidas impopulares e polêmicas, Oswaldo Cruz, além de ter sido o responsável pela estruturação da saúde pública no Brasil, foi quem saneou o Rio, apesar da oposição da mídia e da manifestação popular. Cruz transformou o Rio em um gigantesco laboratório de combate às doenças, implantando métodos revolucionários, causando uma grande indignação, levando a um motim popular, que explodiu em 11 de novembro de 1904, conhecido como a "Revolta da Vacina" [2].

Conforme afirmação de Porto e Ponte [3], as estratégias de vacinaçáo do Brasil têm alcançado altos índices de eficiência, servindo de parâmetro para iniciativas semelhantes em outros países.

O Programa Nacional de Imunizaçóes (PNI), criado em 1971 [4], citado como referência mundial, pois organizou campanhas de vacinação em outros países, como Timor Leste e auxiliou progra- mas de imunizaçôes na Palestina, Cisjordânia e na Faixa de Gaza, estabelecendo cooperação técnica em inúmeros países. Açóes planejadas e sistematizadas desenvolvidas em nosso país erradicaram a varíola em 1973 e a poliomielite em 1989, controlaram o sarampo, o tétano neonatal, as formas graves da tuberculose, a difteria, o tétano acidental e a coqueluche. Ainda na década de 1970, visando à incorporação de novos hábitos e práticas de saúde, o Ministério da Saúde fez ajustes de linguagem à população alvo em suas campanhas, aproximando-se das comunidades e de outras realidades regionais. Os dias nacionais de vacinaçáo adotaram como estratégia a produção de material informativo, como cartazes, folhetos e manuais, veiculados em diversos meios e divulgadores de sua linha de ação. Seu objetivo era despertar a consciência da população para a necessidade da vacina, em especial pais e responsáveis por crianças menores de cinco anos, mobilizando a sociedade em torno dessa questão e envolver outras entidades nesta tarefa. Em 1993, para comemorar os vinte anos do Programa Nacional de Imunizaçóes (PNI), o Zé Gotinha virou a marca das campanhas de multivacinação [2].

A partir do ano 2000, já destacando a história da vacina no Estado do Ceará, houve a introduçáo da vacina contra Haemophilus que contribuiu para a redução dos casos de doenças causadas pela bactéria. Além da meningite, também ocorreu expressiva redução das internações no Ceará e, sobretudo dos óbitos em menores de 5 anos por pneumonia que foram 376 em 1999 e 273 no ano 2000 com redução de 27,4\% em todo o Estado [5]. Em dezembro de 2003, o Ministério da Saúde do Brasil [6] instituiu formalmente um comitê para a preparação de um 
plano que implementou o fortalecimento da vigilância epidemiológica de influenza, a constituição de um estoque estratégico do antiviral e a preparaçáo do Instituto Butantan para a produção da vacina contra a cepa pandêmica. Em 2009 ocorreu uma pandemia do vírus H1N1 [7], inicialmente conhecido por gripe suina, o que fez o Ministério da Saúde começar uma estratégia de vacinaçáo cuja efetividade foi até $95 \%$.

O profissional de enfermagem é personagem externamente atuante nas campanhas de vacinação. Devemos estar atentos para os cuidados de enfermagem para com toda a dinâmica envolvendo a vacinação, desde o armazenamento até as orientaçóes acerca dos efeitos colaterais envolvidos. Esses cuidados devem obedecer aos critérios estabelecidos pelo Ministério da Saúde. Assim este estudo tem o objetivo de informar aos profissionais de saúde sobre os cuidados de enfermagem envolvidos no processo de vacinação.

\section{Material e métodos}

Trata-se de um estudo bibliográfico, descritivo, qualitativo e exploratório. Foram consultados periódicos indexados na Lilacs, Medline, Scielo (Scientific Eletronic Library On Line), entre outros sites da internet e livros de acordo com a terminologia em saúde: imunizaçáo, vacinas, cuidados de enfermagem, rede de frio, técnicas de aplicação de imunobiológicos, para a busca de artigos publicados. A fase de coleta de dados compreendeu o período de 2002 a 2012.

Foi realizada uma pré-análise com um total de 85 artigos obtidos, sendo excluídos 65 por não estarem dentro dos critérios de inclusão. Resultando em 24 referências no final da pesquisa com o tema: Os Cuidados de Enfermagem na Sala de Imunização.

\section{Resultados}

\section{Cuidados de enfermagem na sala de vacinaçáo}

Segundo o Manual Imunizaçóes do Hospital Albert Einstein (MIHIAA), é necessário usar as seguintes técnicas de aplicaçáo das vacinas: Treinamento dos profissionais envolvidos; Posicionamento do cliente para permitir o relaxamento do músculo a ser injetado; Escolha do local apropriado de acordo com a idade, composição corporal e indicação do fabricante da vacina; Escolha da agulha adequada para o local escolhido; Aplicaçáo simultânea de injeções múltiplas por profissionais diferentes pode reduzir a dor de antecipação da próxima injeção; Técnica de anestesia tópica: pode ser utilizada em aplicaçóes intramusculares e diminui a dor da picada da injeção, porém náo tem efeito sobre a dor causada pelo líquido vacinal [8].

O MIHIAA [8] aponta a necessidade de dois aplicadores treinados para a realização da aplicação simultânea. Trabalhos realizados na cidade de Sáo Paulo mostraram que das 231 unidade básicas de saúde com salas de vacinação, os responsáveis são profissionais da enfermagem $98,8 \%$, dos quais $47,9 \%$ enfermeiras e $50,9 \%$ auxiliares e técnicas de enfermagem [9].

\section{Locais de aplicaçáo}

É importante observar os locais corretos para a aplicação dos imunobiológicos para evitar reaçóes adversas. Abaixo se observam os locais mais comuns de aplicação.

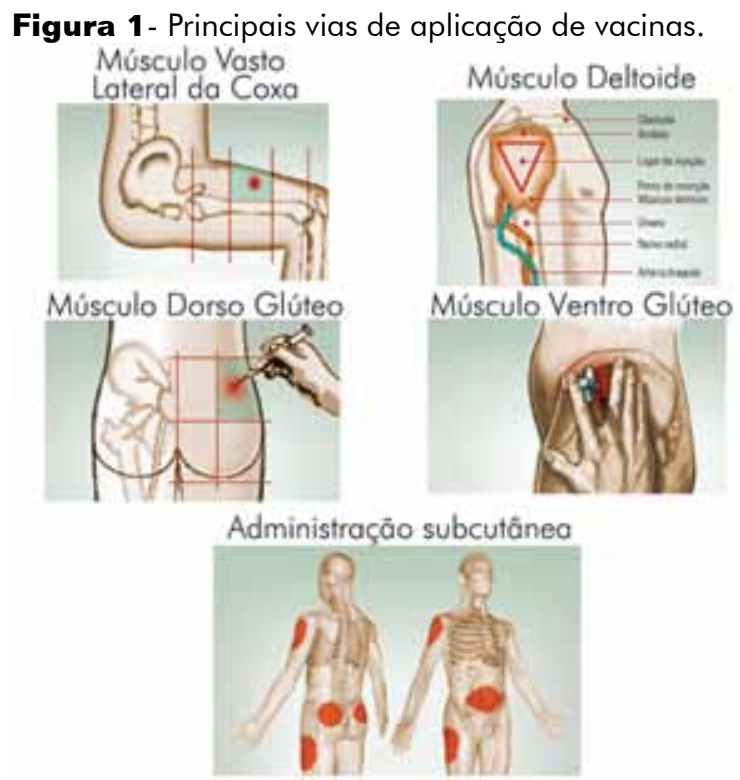

Fonte: Manual de Imunização, 2009.

É comum alguns imunobiológicos causarem efeitos adversos à administração; destes podemos citar: a ocorrência de hipersensibilidade (reação anafilática), após o recebimento de qualquer dose, bem como hipersensibilidade aos componentes de qualquer produto. Para as vacinas bacterianas atenuadas ou de vírus vivo atenuados, considera-se contraindicação a presença de qualquer imunodeficiência congênita ou adquirida, neoplasia maligna e a vigência de tratamento 
com corticoides em dose imunossupressora, terapias imunodepressoras como quimioterapia antineoplásica e radioterapia e presença de gravidez, exceto quando a gestante estiver sob alto risco de exposição a algumas doenças virais imunopreveníveis [10].

Dentre as vacinas que causam reaçóes, e que podemos destacar é a DPT. Ela é uma associação dos toxoides diftéricos e tetânicos e da Bordetella pertussis inativada, tendo o hidróxido ou fosfato de alumínio como adjuvante e o timerosal como preservativo. Pode provocar muitos eventos adversos, porém de pouca gravidade, sendo a maioria nas primeiras 48 horas que se seguem à aplicaçáo da vacina [11].

Um estudo, realizado na Cidade de Campo Grande - MG [11], mostrou que dentre os imunobiológicos que mais apresentaram efeitos adversos pós-vacinação foram: a vacina Dupla Adulto $(26,8 \%)$, a Tetra $(19,5 \%)$ e a DPT $(14,6 \%)$. Enquanto que os efeitos adversos mais presentes foram: dor, rubor, calor $(22,4 \%)$, enduração $(18,4 \%)$ e febre menor ou igual a 39,5(10,5\%).

\section{Cuidados na segurança dos imunobiológicos}

A Rede de Frio ou Cadeia de Frio é o processo de armazenamento, conservação, manipulação, distribuição e transporte dos imunobiológicos do PNI, e deve ter as condiçóes adequadas de refrigeração, desde o laboratório produtor até o momento em que a vacina é administrada [12]. A maioria dos imunobiológicos deve ser conservada a uma temperatura entre $2^{\circ} \mathrm{C}$ e $8^{\circ} \mathrm{C}$. As vacinas de vírus vivos atenuados são mais sensíveis ao calor, com exceção da vacina de rotavírus, que é mais sensível ao frio, não devendo ser congelada. As vacinas para sarampo, rubéola, caxumba, varicela, febre amarela e a BCG tem sensibilidade à luz [13]. O prazo de validade, de acordo com a especificaçáo do fabricante, é de extrema importância e deve ser rigorosamente respeitado.

A organização do refrigerador, principalmente na disposiçáo do imunobiológico, exige um cuidado especial, pois a conservação inadequada pode levar à inativação deste imunobiológico, comprometendo o indivíduo receptor desta vacina [14]. Pesquisa, realizada na cidade de Recife, verificou que apenas em 87,5\% das unidades pesquisadas há condiçôes ideais de conservação, garantindo, assim, a eficácia do imunobiológico e a seguridade das vacinas. Nesse estudo também é apontado que apenas 4,3\% das salas de vacina visitadas estavam adequadas aos requisitos considerados mínimos pelos pesquisadores sobre o controle da Rede de Frio [14]. Melo e colaboradores [15] mostraram que das 39 UBS da Cidade de Recife, $46,1 \%$ das geladeiras apresentavam vedação inadequada e havia inexistência de termômetros de cabo extensor para monitoramento das caixas térmicas.

Dentre outros cuidados preconizados pela FUNASA [12] na organização interna da geladeira (figura 2), podemos citar: No congelador (evaporador): gelo reciclável; Na primeira prateleira: vacinas que podem ser submetidas à temperatura negativa; $\mathrm{Na}$ segunda prateleira: termômetro de máxima e mínima; vacinas que não podem ser submetidas a temperaturas negativas; $\mathrm{Na}$ terceira prateleira: estoque de vacinas; soros; diluentes; $\mathrm{Na}$ prateleira inferior: garrafas com água e um corante; Na porta: não colocar imunobiológicos e náo colocar qualquer outro produto ou objeto. As geladeiras das salas de imunização, não podem ser usadas para guardarem alimentos ou qualquer outro material que náo sejam o material citado assim.

Figura 2 - Modelo de geladeira usada para armazenamento de imunobiológicos e uso incorreto com armazenamento de alimentos.
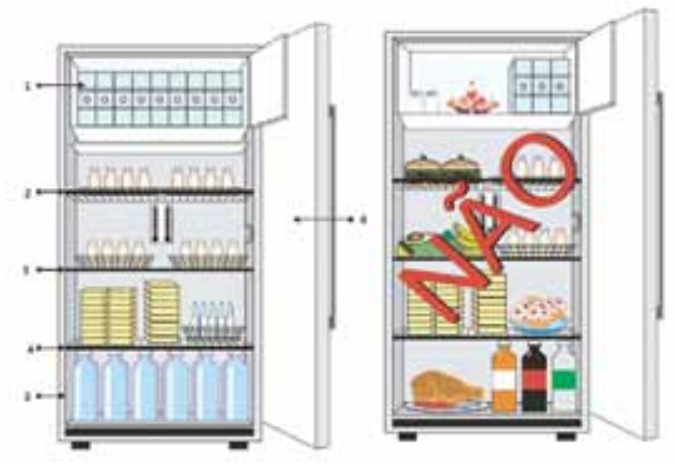

Fonte: (Ministério da Saúde, 2001a).

A Sala de Imunização deve possuir ao menos dois equipamentos básicos utilizados na conservação e armazenamento dos imunobiológicos: um destinado a estocagem (câmara fria ou geladeira doméstica com capacidade igual ou acima 280 litros) e outro para uso diário (refrigeradores tipos refrimed ou caixas térmicas) [12]. Portanto, a ausência de um dos equipamentos básicos poderá gerar falha na qualidade dos imunobiológicos [12].

Segundo Manual de Rede de Frio [12], vemos que no armazenamento das caixas térmicas as vacinas devem estar colocadas juntamente com bobinas de gelo. $\mathrm{O}$ gelo, como elemento mais frio do conjunto, funcionará como receptor do calor do ar e das 
vacinas. Em consequência as vacinas permanecerão mais tempo frias até que o calor transferido para o gelo o faça derreter. Somente a partir desse momento as vacinas passarão a receber calor, já que serão os elementos mais frios do conjunto. Melo e colaboradores mostraram [15] que em Recife das 39 UBS, $41 \%$ dos vacinadores não realizam a ambientaçáo das bobinas de gelo reciclável, 61,5\% não monitoram a temperatura da caixa térmica após o preparo, $38,5 \%$ não trocam as bobinas no início do turno da tarde.

O manual imunização [14] recomenda ainda: instalar a câmara de conservação de vacinas a pelo menos $20 \mathrm{~cm}$ da parede e longe de fontes produtoras de calor; tomada única para ligação da câmara de conservação; usar a câmara exclusivamente para os imunobiológicos (Figura 2); manter controle rigoroso da temperatura da câmara, seja através de verificação periódica ou através de sistema de alarme; conservar bobinas de gelo reciclável para manter por mais tempo a temperatura, em caso de falta de energia elétrica; colocar as vacinas com prazo de validade próximo do vencimento nas prateleiras $\mathrm{da}$ frente; colocar as vacinas de vírus vivo na primeira prateleira (a mais próxima do congelador) e deixar um espaço livre entre as caixas de vacinas.

\section{Necessidade de aperfeiçoamento técnico}

Em um estudo realizado na cidade de Iguatu, Estado do Ceará, no período de agosto a novembro de 2009, o autor destaca a necessidade dos profissionais da Sala de Vacinação de realizarem cursos de aprimoramento profissional, dando assim, maior capacidade aos profissionais da sala de imunização. Em sua pesquisa foram entrevistados 10 profissionais que trabalham na sala de imunização e o resultado mostrou que apenas dois funcionários fizeram o curso de aperfeiçoamento, o que mostra uma deficiência importante na qualidade do pessoal deste setor [16]. Um trabalho realizado nas Unidades Básicas de Saúde de uma cidade de Minas Gerais com os profissionais de saúde que trabalhavam diretamente na sala de imunização, somente $37,1 \%$ tinham capacitação em imunização [17].

\section{Orientaçóes prestadas aos usuários com relação às vacinas}

Oliveira et al. [17] destacam que uma das principais atividades realizadas pelos profissionais da sala de vacinação é em relação às orientaçóes prestadas aos usuários com relação às vacinas, tais como: quais as vacinas que devem tomar, as possíveis reaçôes adversas, aprazamento, dentre outras informaçóes relacionadas aos imunobiológicos. Esse autor realizou um estudo na cidade de Natal-RN sobre essas condutas de orientação e/ou informaçóes que apresentou os seguintes resultados: apenas 46,5\% realizavam orientaçôes sobre as reaçôes adversas, $30,2 \%$ não orientavam as mães, $14,0 \%$ não orientavam sobre as vacinas administradas e apenas 9,3\% recebiam orientaçóes sobre aprazamento. No estudo de Luna et al. [18], em estudo realizado na cidade de Fortaleza, observaram que $72,7 \%$ explicavam o procedimento, enquanto $27,3 \%$ náo realizavam essas orientaçóes.

\section{Quanto à exclusividade da Sala de Imunizaçáo}

Em um estudo realizado no ano de 2007 na cidade de Fortaleza, na Secretaria Executiva Regional IV (SER-IV) com as enfermeiras atuantes na sala de imunização, foram encontrados os seguintes resultados: quanto à disposição de material suficiente: $88,9 \%$, afirmaram que tinham material suficiente, contra $11,1 \%$ que afirmaram que náo havia material suficiente. Em relação à disponibilidade de material disponível: todos afirmaram que o material presente na sala de imunização era suficiente. Já no item em que apontava a exclusividade da sala para a vacinação: $88,9 \%$ afirmaram ser a sala exclusiva para vacinação; entretanto $11.1 \%$ afirmaram ser a sala usada para outros procedimentos [18].

\section{Higienizaçáo das mãos}

As mãos constituem a principal via de transmissão de microrganismo durante a assistência prestada aos pacientes. A prática do lavar das mãos é a mais importante profilaxia contra as infecçóes, que, conjugada a outras estratégias, constitui medidas imprescindíveis para o controle de infecção no ambiente hospitalar $[18,19]$. A concentração de bactérias na pele normal das mãos é de $10^{4}$ a $10^{6}$ Unidades Formadoras de Colônia (UFC) $/ \mathrm{cm}^{2}$ [20]. Os principais patógenos hospitalares encontrados nas mãos são: Staphylococus aureus, S. epidermidis, Enterococus spp. Pseudomonas aeruginosa, Klebisiella $s p p$., leveduras como Candida e vírus como vírus da hepatite ; vírus respiratórios, vírus de transmissão fecal-oral como rotavirus, dentre outros $[21,22]$. 
Luna et al. [18] ainda expóe no estudo a rotina de higienização das mãos em seu estudo, mostrando que $91,7 \%$ dos profissionais lavam as mãos durante os procedimentos, enquanto que $8,3 \%$, não realizavam essa higienização. Soares et al. [23] mostraram que maior é a adesão a esse procedimento, quanto mais fácil for a disponibilidade dos materiais e sua proximidade em relação ao posto de trabalho.

\section{Cuidados quanto à limpeza}

Recomenda-se que a limpeza da geladeira dos imunobiológicos deve ser realizada com frequência. Deve ser feita periodicamente, a cada 15 dias, ou quando a camada de gelo atingir 0,5 centímetros [12]. Em um estudo realizado em município mineiro da Macrorregional Oeste, quanto à limpeza e o degelo do refrigerador de imunobiológicos, 51,4\% responderam que realizam a limpeza a cada 15 dias, $8,6 \%$ não sabem ou não responderam, e 40,0\% dos entrevistados responderam que realizam o procedimento de acordo com uma periodicidade que não está em consonância com orientaçôes do PNI [24]. A sala de vacina, local para administração de vacinas na Unidade de Saúde da Família (USF), deve estar devidamente limpa e organizada, prevenindo infecçóes e proporcionando ao usuário assistência segura e de qualidade [24].

\section{Conclusão}

O trabalho do enfermeiro na sala de vacinação não está relacionado a meras atividades, mas a ações que exigem muito conhecimento técnico e habilidade na execução das tarefas competentes aos profissionais da sala de imunização.

\section{Referências}

1. Schatzmayr HG. Vacinas no limiar do século. Biotecnologia Ciência e Desenvolvimento 1997;1(2):40-43.

2. Porto MY. Uma revolta popular contra a vacinação. Cienc Cult 2003;55(1):53-4.

3. Porto A, Pontes CF. Vacinas e campanhas: imagens de uma história a ser contada. Revista História, Ciências, Saúde - Manguinhos 2003;10;725-42.

4. Feijó RB, Sáfadi MAP. Imunizaçôes: três séculos de uma história de sucessos e constantes desafios. J Pediatr 2006;82(3):S1-S3.

5. Soares BR, Campos JS, Nunes NM. Avanços em imunizaçóes. Revista de Pediatria do Ceará 2002;3(3):13-9.

6. Andrade CR, Ibiapina CC, Champs NS, Toledo Junior ACC, Picinin IFM. Gripe aviária: a ameaça do século XXI. J Bras Pneumol 2009;35(5):470-9.
7. Carneiro M, Pina FJT, Waib LF, Motta FLP. Influenza H1N1 2009: revisão da primeira pandemia do século XXI. Revista AMRIGS 2010;52(2);206-13.

8. Manual de Imunização: Centro de Imunizações Hospital Israelita Albert Einstein/Alfredo Elias Gilio. Rio de Janeiro: Elsevier; 2009.

9. Aranda CMSS, Moraes JC. Rede de frio para a conservaçáo de vacinas em unidades públicas do município de São Paulo: conhecimento e prática. Rev Bras Epidemiol 2006;9(2):172-85.

10. Ministério da Saúde. Manual de procedimentos para vacinação. Brasília: Fundação Nacional de Saúde; 2001c.

11. Piacentini S, Contrera-Moreno L. Eventos adversos pós-vacinais no município de Campo Grande (MS, Brasil). Ciênc Saúde Coletiva 2011;6(2):531-6.

12. Ministério da Saúde. Fundaçáo Nacional de Saúde Manual de rede de frio. 3a ed. Brasília: Funasa; 2001a.

13. Ministério da Saúde. A situação epidemiológica mundial da influenza e a preparação do Brasil para uma pandemia. Brasília: Ministério da Saúde; 2009.

14. Araujo ACM, Silva MRF, Frias PG. Avaliação da Rede de Frio do Programa Municipal de Imunização do Distrito Sanitário IV do Município do Recife. Revista de APS 2009;12(3):238-42.

15. Melo GKM, Oliveira JV, Andrade MS. Aspectos relacionados à conservação de vacinas nas unidades básicas de saúde da cidade de Recife-Pernambuco. Epidemiologia e Serviços de Saúde 2010;19(1):25-32.

16. Feitosa L, Feitosa J, Coriolano M. Conhecimentos e práticas do auxiliar de enfermagem em sala de imunização. Cogitare Enferm 2010;12(3):238-42.

17. Oliveira VG, Pedrosa KKA, Monteiro AI, Santos ADB. Vacinação: O fazer da enfermagem e o saber das mães e/ou cuidadores. Rev Rene 2010;11:133-41.

18. Luna GLM, Lira SVG, Moreira DP, Pereira AS. Aspectos relacionados à administração e conservação de vacinas em centros de saúde no Nordeste do Brasil. Ciênc Saúde Coletiva 2011;16(2):513-21.

19. Smeltzer SC, Bare BG. Brunner \& Suddarth. Tratado de Enfermagem Médico-Cirúrgico. $11^{\mathrm{a}} \mathrm{ed}$. Rio de Janeiro: Guanabara Koogan; 2009.

20. Krampf G, Kramer A. Epidermiologic background of hand hygiene and evaluation of the most important agents for scrubs and rubs. Clin Microbiol Rev 2004;(4):863-893.

21. Agência Nacional de Vigilância Sanitária. Higienização das mãos em serviços de saúde. Brasília: Anvisa; 2007.

22. Cardoso CL, Mimica LMJ. Aspectos microbiológicos da pele in: Brasil, Agência Nacional de Vigilância Sanitária. Segurança do Paciente - Higienização das mãos. Brasília: Anvisa; 2007. p. 17-19.

23. Soares CMB, Miranda NM, Carvalho SM, Paixão CAP. Higienização das mãos: Opinião de enfermeiros e técnicos de enfermagem de um hospital universitário de Minas Gerais. Revista Panamericana de Infectologia 2012;14(1):17-21.

24. Oliveira VC, Guimarães EAA, Guimarães IA, Januário LH, Ponto IC. Prática da enfermagem na conservação de vacinas. Acta Paul Enferm 2009;22(6):814-8. 